\title{
Chronic inflammation and the growth hormone/insulin-like growth factor-1 axis
}

\author{
EWELINA WITKOWSKA-SĘDEK, BEATA PYRŻAK
}

Department of Paediatrics and Endocrinology, Medical University of Warsaw, Warsaw, Poland

\begin{abstract}
Interactions between growth hormone $(G H)$, insulin-like growth factor-1 (IGF-1), and the immune system are complex, bidirectional, but not fully explained. Current reviews based on numerous studies have indicated that chronic inflammation could suppress the GH/IGF-1 axis via several mechanisms such as relative GH and/or IGF-1 insufficiency, peripheral resistance to GH and/or IGF-1 resulting from down-regulation of GH and IGF-1 receptors, disruption in the GH/IGF-1 signalling pathways, dysregulation of IGF binding proteins (IGFBPs), reduced IGF bioavailability, and modified gene regulation due to changes in the microRNA system. It is well-known that relationships between the immune system and the GH/IGF-1 axis are mutual and GH as well as IGF-1 could modulate inflammatory response and the activity of systemic inflammation. Available data indicate that the GH/IGF-1 axis exerts both pro-inflammatory and anti-inflammatory effects. Pro-inflammatory cytokines such as interleukin-6 (IL-6), tumour necrosis factor- $\alpha(T N F-\alpha)$, and interleukin-1 $\beta(I L-\beta)$ are some of the most significant factors, besides malnutrition, chronic stress, and prolonged use of glucocorticoids, which impair the activity of the GH/IGF-1 axis, and consequently lead to growth retardation in children suffering from childhoodonset chronic inflammatory diseases. In this review, we discuss the mechanisms underlying the impact of chronic inflammation on the GH/IGF-1 axis and growth processes during childhood and adolescence, based on a number of experimental and human studies.
\end{abstract}

Key words: pro-inflammatory cytokines, growth hormone, insulin-like growth factor-1, growth impairment, children and adolescents.

(Cent Eur J Immunol 2020; 45 (4): 469-475)

\section{Introduction}

Complex interactions between the growth hormone $(\mathrm{GH})$, insulin-like growth factor-1 (IGF-1), and the immune system have been confirmed, but not fully explained [1-7]. Current reviews based on numerous studies have indicated that chronic inflammation could suppress the GH/IGF-1 axis via several mechanisms such as relative GH and/or IGF-1 insufficiency, peripheral resistance to $\mathrm{GH}$ and/or IGF-1 resulting from down-regulation of GH and IGF-1 receptors, disruption in the GH/IGF-1 signalling pathways, dysregulation of IGF binding proteins (IGFBPs), reduced IGF bioavailability, and modified gene regulation due to changes in the microRNAs (miRNAs) system [1, 8-10]. On the other hand, it is well-known that relationships between the immune system and the GH/IGF-1 axis are mutual, and GH as well as IGF-1, which is the main mediator of its action, could modulate inflammatory response and the activity of systemic inflammation [4, 11-13]. Available data indicate that the GH/IGF-1 axis exerts both pro-inflammatory and anti-inflammatory effects $[4,11,14-17]$.
The main role of the GH/IGF-1 axis is to promote postnatal linear growth in children and adolescents. In fact, the GH/IGF-1 axis exerts a number of additional effects including modulation of carbohydrate, lipid, protein and mineral metabolism, and controlling of aging, cancer development, and a number of physiological processes related mainly to the cardiovascular and renal systems [18-22]. $\mathrm{GH}$ is produced in, and released from, the anterior pituitary somatotrophs. Its secretion is regulated mainly by two hypothalamic hormones, the growth hormone-releasing hormone and somatostatin (growth hormone-inhibiting hormone), and by the GH secretagogue ghrelin, released primarily by the stomach, but also by the hypothalamus, pituitary, lung, adrenal cortex, kidney, bone, testis, placenta, pancreatic islet cells, and intestinal tract [19, 23-25]. GH acts directly on the GH receptor (GHR) located mainly in epiphyseal plates in long bones and spine, liver, muscles, and adipose tissue or indirectly via initiating IGF-1 production by the hepatocytes $[19,24,26]$. GH binding to its receptor leads to activation of tyrosine kinase, Janus kinase 2 (JAK2), and tyrosyl phosphorylation of both

Correspondence: Ewelina Witkowska-Sędek, Department of Paediatrics and Endocrinology, Medical University of Warsaw, 63A Żwirki i Wigury St., 02-091 Warsaw, Poland, e-mail: ewelina.witkowska-sedek@wum.edu.pl Submitted: 25.10.2020; Accepted: 6.11.2020

This is an Open Access article distributed under the terms of the Creative Commons Attribution-NonCommercial-ShareAlike 4.0 International (CC BY-NC-SA 4.0). License (http://creativecommons.org/licenses/by-nc-sa/4.0/) 
JAK2 and GHR. These changes result in recruitment to GHR of a number of molecules, including a signal transducer and activator of transcription (STAT) 1, 3, 5a, and $5 \mathrm{~b}$, mitogen-activated protein kinases (MAPKs), insulin receptor substrates, and intracellular calcium, which are crucial for GH signalling [19, 27]. IGF-1, produced mainly in the liver but also locally in several tissues, is involved in regulation of proliferation, differentiation, and apoptosis in many cell types. It circulates bound to IGFBPs, which act as transport proteins, modulate IGF-1 bioavailability, prolong its half-life, and regulate its activity in target tissues and clearance [8, 28-30].

A number of studies, both experimental and clinical, were conducted to better explain the impact of chronic inflammation on postnatal growth and pubertal development during childhood. It has been confirmed that the effects of pro-inflammatory cytokines, such as interleukin 6 (IL-6), tumour necrosis factor- $\alpha(\mathrm{TNF}-\alpha)$, and interleukin $1 \beta$ (IL-1 $\beta$ ), are some of the most significant factors, besides malnutrition, chronic stress, and prolonged use of glucocorticoids, which impair the activity of the GH/IGF-1 axis, and consequently lead to growth retardation in children suffering from childhood-onset chronic inflammatory diseases [8, 10, 23, 31-38]. In everyday clinical practice, the most common chronic inflammatory diseases associated with growth impairment are inflammatory bowel disease (IBD) - especially Crohn's disease, cystic fibrosis (CF), and juvenile idiopathic arthritis (JIA) [8, 9, 28, 39, 40].

In this review, we discuss the mechanisms underlying the impact of chronic inflammation on the GH/IGF-1 axis action and growth processes during childhood and adolescence, based on a number of experimental and human studies.

\section{A summary of the animal model and human studies}

Numerous studies have confirmed close relationships between chronic inflammation, especially colitis and arthritis, and somatic growth and development. Most of them focused on the impact on those processes of IL-6, TNF- $\alpha$, and IL- $1 \beta$, which seem to be the main pro-inflammatory cytokines involved in such interactions [9, 28, 41, 42]. Current data indicate that IL- 6 , TNF- $\alpha$, and IL- $1 \beta$ could affect the GH/IGF-1 axis through both systemic and local mechanisms, acting individually or in combination. Systemic action of pro-inflammatory cytokines leads mainly to hepatic GH resistance and suppression of IGF-1 action in target tissues, while their local action directly affects the growth plate [2, 28, 31, 41-45]. It has been confirmed that IL-6 could suppress GH action leading to reduction in JAK/STAT signalling by induction of suppressor of cytokine signalling (SOCS)-3 protein $[1,46]$. IL- $1 \beta$ could impair GH signalling acting on the expression of STAT3 and STAT5 $[1,47]$. Moreover, IL-6, IL-1 $\beta$, and TNF- $\alpha$ could inhibit IGF-1 action by dysregulation of its intracellular mediators, such as MAPK/extracellular signal-regulated kinases and phosphoinositide 3-kinase (PI3K) in chondrocytes $[1,32,48]$. It has also been confirmed that IL-1 $\beta$ and TNF- $\alpha$ suppress gonadal sex steroid production in Leydig cells and ovarian cells and decrease hypothalamic secretion of gonadotropin-releasing hormone $(\mathrm{GnRH})$, which results in delayed puberty and consequently aggravates growth retardation [49-51].

\section{Systemic effects of pro-inflammatory cytokines on the GH/IGF-1 axis}

Numerous studies indicate that inflammation-induced hepatic $\mathrm{GH}$ resistance results from two main mechanisms. The first mechanism is downregulation of GHR and the second is the upregulation of the members of the SOCS family, especially SOCS1 and SOCS3, which contribute to the negative regulation of the growth-promoting actions of $\mathrm{GH}[2,23,28,52-55]$. TNF- $\alpha$ and IL- $1 \beta$ primarily inhibit hepatic GHR expression, while IL-6 inhibits hepatic GH signalling by inducing SOCS3 expression and has no effect on GHR expression [2, 28, 53, 56-58]. Experimental data by Zhao et al. [2] show that neutralisation of TNF- $\alpha$ and IL-1 $\beta$ in mouse inflammation models does not significantly alter SOCS3 expression stimulated by the inflammation process but restore GHR and IGF-1 expression suppressed by inflammation. On the other hand, neutralisation of IL-6 does not alter inflammation-suppressed GHR expression, but significantly reduces inflammation-stimulated SOCS3 expression and restores IGF-1 expression. Moreover, IL-6 action seems to be superseded by TNF- $\alpha$ and IL-1 $\beta$ [2].

Despite inducing hepatic GH resistance, pro-inflammatory cytokines could systemically suppress IGF-1 action by influencing the metabolism of IGFBPs and consequently IGF-1 clearance. De Benedetti et al. [31] confirmed, using the transgenic mouse model with growth defective phenotype (NSE-hIL-6 mice), that overexpression of IL-6 early after birth leads to a 50-70\% size reduction compared to normal non-transgenic mice due to a decrease in circulating IGF-1 levels. Simultaneously, that effect was partially reverted by the administration of a monoclonal antibody to the murine IL-6 receptor. The authors also emphasise that those changes were accompanied by normal distribution of GH pituitary cells and normal GH production and secretion [31]. More recent studies by De Benedetti et al. $[59,60]$ showed that NSE/hIL-6 mice had normal liver IGF-1 production, while IGF-binding protein 3 (IGFBP-3) levels were decreased and serum proteolysis of IGFBP-3 was increased. A reduction in IGFBP-3 levels resulted in a significant decrease in the circulating $150-\mathrm{kDa}$ ternary complex (IGF-1/IGFBP-3/acid labile subunit complex), which led to a reduction in IGF-1 half-life and to acceleration of IGF-1 clearance. Secondary to those changes, IGF-1 serum levels were decreased [59, 60]. 


\section{Local effects of pro-inflammatory cytokines on the growth plate}

The epiphyseal growth plates, located in the proximal and distal parts of the long bones, are the final target organs for growth factors [8]. Negative direct local effects of pro-inflammatory cytokines on the growth plate have been reported by many authors [32, 44, 61-63]. It has also been confirmed that a combination of IL-1 $\beta$, IL-6, and TNF- $\alpha$ enhances their growth inhibitory effects [44, 45, 63]. Martensson et al. [44] showed, in a model of cultured foetal rat metatarsal bones, that TNF- $\alpha$ and IL- $1 \beta$ could act in synergy at the growth plate chondrocytes to inhibit longitudinal growth due to a decrease in chondrocyte proliferation and an increase in its apoptosis. Simultaneously, the authors noticed that this effect could be partially reversed by IGF-1 [44]. MacRae et al. [45] confirmed a dose- and duration-dependent inhibitory effect of IL- $1 \beta$ and TNF- $\alpha$ on metatarsal growth and concluded that the extent of recovery following cytokine exposure may be incomplete following longer periods of exposure [45]. On the other hand, it is worth noting that both TNF- $\alpha$ and IL- $1 \beta$, produced endogenously in the growth plate chondrocytes, seem to play a role in normal growth, while the above-mentioned negative effects of those cytokines on chondrocytes have been seen at their supraphysiological levels [42, 61, 64]. Experimental studies have also confirmed that IL- 6 could act locally at the growth plate chondrocytes [62, 63, 65]. Nakajima et al. [62] reported that IL-6 leads to inhibition of early differentiation of ATDC5 chondrogenic progenitor cells and could be considered as a cellular-level factor in growth retardation in systemic JIA. Moreover, IL-1 $\beta$, IL-6, and TNF- $\alpha$ could affect the function of the growth plate by suppressing IGF-1 intracellular signalling and by inhibiting the effect of IGF-1 on chondrocytes proliferation and differentiation at the growth plate $[9,32]$.

\section{The effects of childhood-onset chronic inflammatory diseases on longitudinal growth}

Chronic inflammation could lead to significant growth retardation in children and adolescents [59, 65-68]. Experimental data indicate that this effect is independent of undernutrition and occurs even in well-nourished patients [28, 69-71]. It is also emphasised that the degree of growth retardation correlates with the activity of the inflammatory disease [9]. Abnormalities reported in the GH/IGF-1 axis in patients with chronic inflammatory diseases are manifold. Increased levels of pro-inflammatory cytokines are related positively to the activity of the disease and adversely to IGF-1 and IGFBP-3 levels in patients with IBD [66, 67], JIA $[31,65,72,73]$, and CF $[68,74]$. Those changes usually coexist with normal physiological or stimulated serum $\mathrm{GH}$ levels, which confirms a state of GH resistance, but other mechanisms of growth impairment are also considered $[9,28,42,38,75,76]$. On the other hand, it should be taken into account that IGF-1 as a valuable laboratory indicator of nutritional status could be decreased in states of poor nutrition due to limited nutrient intake and malabsorption, which often accompany chronic inflammation [23, 28, 69]. Serum levels of IGFBP-3 do not seem to be as dependent on nutritional deprivation as IGF-1, and they better reflect GH signalling [77].

The study by Bozzola et al. [78] indicates that GH resistance observed in JIA children results from a significant reduction in GHR gene expression, which is related to the activity of the disease. The authors noticed that the restoration of both GHR mRNA gene expression and IGF-1 secretion observed after 2 years of JIA therapy correlated with a reduction in the activity of the disease expressed as a decrease in IL-6 levels [78]. Other postulated mechanisms that could result in growth retardation in JIA children are decreased pituitary GH secretion, which was observed both in children treated with systemic glucocorticoids [79] and also independently of such therapy [80], decreased IGFBP-3 levels due to increased IGFBP-3 proteolysis [59], and relative resistance to IGF-1, reported mainly in patients treated with glucocorticoids $[81,82]$. MacRae et al. [83] reported significant impairment in chondrogenesis at the growth plate and consequently in the growth of cultured murine metatarsal exposed to serum and synovial fluid obtained from JIA children. It is noteworthy that effects observed after using synovial fluid were resistant to treatment with IL-1 $\beta$, IL-6, and TNF- $\alpha$ specific antibodies and IGF-1, which suggest that other factors presented in those fluid also have an effect on longitudinal growth through IGF-1-independent mechanisms [83].

In children with IBD growth retardation seems to be related mainly to GH resistance, but low IGF-1 levels reported in that group of patients may result not only from the inflammation process itself, but also from malnutrition and prolonged use of glucocorticoids [9, 23, 35, 84]. The number of studies evaluating IGFBP metabolism in those patients is not satisfactory $[9,28]$. Despite the wide range of abnormalities in both GH and IGF-1 secretion (functional deficiency) and sensitivity (systemic and/or hepatic resistance), which has been reported in IBD children, the exact mechanisms of the associations between activity of the disease and the GH/IGF-1 axis are not clear $[9,28$, 85-90].

Results of studies evaluating the GH/IGF-1 axis in patients with $\mathrm{CF}$ confirm relative resistance to $\mathrm{GH}$, but data concerning the pattern of $\mathrm{GH}$ secretion are scarce [9, 68, 91-93]. Ciro et al. [91] reported both GH insufficiency and reduced IGF-1 levels in CF children. They concluded that impaired $\mathrm{GH}$ secretion is more frequent among $\mathrm{CF}$ patients compared to the prevalence of GH deficiency in the general population [91]. An overall reduction in IGF bioactivity has also been reported in that group of patients 
due to abnormalities in IGFBPs levels, mainly reduced IGFBP-3 levels and increased IGFBP-1 and IGFBP-2 [68, 94, 95]. Moreover, it has been confirmed that IGF-1 and IGFBP-3 levels are associated with lung function parameters, such as forced expiratory volume in 1 second (FEV1) and forced vital capacity [95-97].

In light of the studies conducted in the last few years, it should also be emphasised that changes in the miRNAs seem to be additional factors linking chronic inflammation and growth retardation observed in childhood-onset chronic inflammatory diseases $[1,8]$. Numerous studies indicate that miRNAs, as post-transcriptional regulators of gene expression, could impact a number of proteins and cytokines, which are involved in the control of the GH/ IGF-1 axis [98-102]. The mechanisms of those associations, their biological role, and clinical utility requires further investigation.

\section{Conclusions}

In summary, the immune system and especially chronic inflammation exert significant effects on the GH/IGF-1 axis and longitudinal growth. Those relationships seem to be multi-faceted, often coexisting with other factors such as malnutrition and prolonged use of glucocorticoids, which significantly hampers efforts to precisely explain these mechanisms. Available data indicate that supraphysiological levels of pro-inflammatory cytokines lead mainly to $\mathrm{GH}$ resistance but could also impair IGF-1 signalling and metabolism of IGFBPs.

\section{The authors declare no conflict of interest.}

\section{References}

1. Cirillo F, Lazzeroni P, Catellani C, et al. (2018): MicroRNAs link chronic inflammation in childhood to growth impairment and insulin-resistance. Cytokine Growth Factor Rev 39: 1-18.

2. Zhao Y, Xiao X, Frank SJ, et al. (2014): Distinct mechanisms of induction of hepatic growth hormone resistance by endogenous IL-6, TNF- $\alpha$, and IL-1 $\beta$. Am J Physiol Endocrinol Metab 307: E186-E198.

3. Ahmed SF, Farquharson C (2010): The effect of GH and IGF1 on linear growth and skeletal development and their modulation by SOCS proteins. J Endocrinol 206: 249-259.

4. Hattori N (2009): Expression, regulation and biological actions of growth hormone (GH) and ghrelin in the immune system. Growth Horm IGF Res 19: 187-197.

5. O'Connor JC, McCusker RH, Strle K, et al. (2008): Regulation of IGF-I function by proinflammatory cytokines: at the interface of immunology and endocrinology. Cell Immunol 252: 91-110.

6. Ahmed SF, Sävendahl L (2009): Promoting growth in chronic inflammatory disease: lessons from studies of the growth plate. Horm Res 72: 42-47.

7. Sävendahl L (2012): The effect of acute and chronic stress on growth. Sci Signal 5: pt9.
8. Cirillo F, Lazzeroni P, Sartori C, Street ME (2017): Inflammatory diseases and growth: effects on the GH-IGF axis and on growth plate. Int J Mol Sci 18: 1878.

9. Wong SC, Dobie R, Altowati MA, et al. (2016): Growth and the growth hormone-insulin like growth factor 1 axis in children with chronic inflammation: current evidence, gaps in knowledge, and future directions. Endocr Rev 37: 62-110.

10. Soendergaard C, Young JA, Kopchick JJ (2017): Growth hormone resistance - special focus on inflammatory bowel disease. Int J Mol Sci 18: 1019.

11. Andreassen M, Frystyk J, Faber J, Kristensen L ̌ (2012): GH activity and markers of inflammation: a crossover study in healthy volunteers treated with GH and a GH receptor antagonist. Eur J Endocrinol 166: 811-819.

12. Mukherjee A, Helbert M, Davis J, et al. (2010): Immune function in hypopituitarism: time to reconsider? Clin Endocrinol (Oxf) 73: 425-431.

13. Smith TJ (2010): Insulin-like growth factor-I regulation of immune function: a potential therapeutic target in autoimmune diseases? Pharmacol Rev 62: 199-236.

14. Hochdörfer T, Kuhny M, Zorn CN, et al. (2011): Activation of the PI3K pathway increases TLR-induced TNF- $\alpha$ and IL- 6 but reduces IL-1 $\beta$ production in mast cells. Cell Signal 23: 866-875.

15. Andreassen M, Vestergaard H, Kristensen Ľ̌ (2007): Concentrations of the acute phase reactants high-sensitive C-reactive protein and YKL-40 and of interleukin 6 before and after treatment in patients with acromegaly and growth hormone deficiency. Clin Endocrinol 67: 909-916.

16. Bozzola M, De Amici M, Zecca M, et al. (1998): Modulating effect of human growth hormone on tumour necrosis factor-alpha and interleukin-1beta. Eur J Endocrinol 138: 640-643.

17. Villares R, Criado G, Juarranz Y, et al. (2018): Inhibitory Role of Growth Hormone in the Induction and Progression Phases of Collagen-Induced Arthritis. Front Immunol 9: 1165.

18. Dehkhoda F, Lee C, Medina J, et al. (2018): The growth hormone receptor: mechanism of receptor activation, cell signaling, and physiological aspects. Front Endocrinol 9: 35.

19. Lu M, Flanagan JU, Langley RJ, et al. (2019): Targeting growth hormone function: strategies and therapeutic applications. Sig Transduct Target Ther 4: 3 .

20. Witkowska-Sedek E, Labochka D, Stelmaszczyk-Emmel A, et al. (2018): Evaluation of glucose metabolism in children with growth hormone deficiency during long-term growth hormone treatment. J Physiol Pharmacol 69: 10.26402/ jpp.2018.2.08.

21. Rothermel J, Reinehr T (2016): Metabolic alterations in paediatric GH deficiency. Best Pract Res Clin Endocrinol Metab 30: 757-770.

22. Masternak MM, Bartke A (2012): Growth hormone, inflammation and aging. Pathobiol Aging Age Relat Dis 2: 10.3402/ pba.v2i0.17293.

23. Fazeli P, Klibanski A (2014): Determinants of GH resistance in malnutrition. J Endocrinol 220: R57-R65.

24. Ranke MB, Wit JM (2018): Growth hormone - past, present and future. Nat Rev Endocrinol 14: 285-300.

25. Ibrahim Abdalla MM (2015): Ghrelin-Physiological Functions and Regulation. Eur Endocrinol 11: 90-95.

26. Bidlingmaier M, Strasburger CJ (2010): Growth hormone. Handb Exp Pharmacol 195: 187-200.

27. Carter-Su C, Schwartz J, Smit LS (1996): Molecular mechanism of growth hormone action. Annu Rev Physiol 58: 187-207. 
28. Wong SC, Macrae VE, McGrogan P, Ahmed SF (2006): The role of pro-inflammatory cytokines in inflammatory bowel disease growth retardation. J Pediatr Gastroenterol Nutr 43: 144-155.

29. Firth SM, Baxter RC (2002): Cellular actions of the insulin-like growth factor binding proteins. Endocr Rev 23: 824854.

30. Haywood NJ, Slater TA, Matthews CJ, et al. (2019): The insulin like growth factor and binding protein family: novel therapeutic targets in obesity \& diabetes. Mol Metab 19: 86-96.

31. De Benedetti F, Alonzi T, Moretta A, et al. (1997): Interleukin- 6 causes growth impairment in transgenic mice through a decrease in insulin-like growth factor-I. A model for stunted growth in children with chronic inflammation. J Clin Investig 99: 643-650.

32. Choukair D, Hügel U, Sander A, et al. (2014): Inhibition of IGF1-related intracellular signaling path- ways by proinflammatory cytokines in growth plate chondrocytes. Pediatr Res 76: 245-251.

33. Ezri J, Marques-Vidal P, Nydegger A (2012): Impact of disease and treatments on growth and puberty of pediatric patients with inflammatory bowel disease. Digestion 85: 308-319.

34. Meazza C, Pagani S, Gertosio C, et al. (2014): Celiac disease and short stature in children. Expert Rev Endocrinol Metab 9: $535-542$.

35. Gasparetto M, Guariso G (2014): Crohn's disease and growth deficiency in children and adolescents. World J Gastroenterol 20: 13219-13233.

36. Bechtold S, Simon D (2014): Growth abnormalities in children and adolescents with juvenile idiopathic arthritis. Rheumatol Int 34: 1483-1488.

37. Le TN, Anabtawi A, Putman MS, et al. (2019): Growth failure and treatment in cystic fibrosis. J Cyst Fibros 18: S82-S87.

38. DeBoer MD, Scharf RJ, Leite AM, et al. (2017): Systemic inflammation, growth factors, and linear growth in the setting of infection and malnutrition. Nutrition 33: 248-253.

39. Simon D (2010): Inflammation and growth. J Pediatr Gastroenterol Nutr 51: S133-S134.

40. Ishige $T$ (2019): Growth failure in pediatric onset inflammatory bowel disease: mechanisms, epidemiology, and management. Transl Pediatr 8: 16-22.

41. MacRae VE, Wong SC, Farquharson C, et al. (2006): Cytokine actions in growth disorders associated with pediatric chronic inflammatory diseases (review). Int J Mol Med 18: 1011-1018.

42. Sederquist B, Fernandez-Vojvodich P, Zaman F, et al. (2014): Recent research on the growth plate: Impact of inflammatory cytokines on longitudinal bone growth. J Mol Endocrinol 53: T35-T44.

43. Li P, Schwarz EM (2003): The TNF- $\alpha$ transgenic mouse model of inflammatory arthritis. Springer Semin Immunopathol 25: 19-33.

44. Martensson K, Chrysis D, Savendahl L (2004): Interleukin-1 $\beta$ and TNF- $\alpha$ act in synergy to inhibit longitudinal growth in fetal rat metatarsal bones. J Bone Miner Res 19: 1805-1812.

45. MacRae VE, Farquharson C, Ahmed SF (2006): The restricted potential for recovery of growth plate chondrogenesis and longitudinal bone growth following exposure to pro-inflammatory cytokines. J Endocrinol 189: 319-328.

46. Thissen JP (2007): How proinflammatory cytokines may impair growth and cause muscle wasting. Horm Res 67: 64-70.

47. Boisclair YR, Wang J, Shi J, et al. (2000): Role of the suppressor of cytokine signaling-3 in mediating the inhibitory effects of interleukin-1beta on the growth hormone-dependent transcription of the acid-labile subunit gene in liver cells. J Biol Chem 275: 3841-3847.

48. Broussard SR, McCusker RH, Novakofski JE, et al. (2004): IL-1 beta impairs insulin-like growth factor i-induced differentiation and downstream activation signals of the insulin-like growth factor i receptor in myoblasts. J Immunol 172: 77137720.

49. Hong CY, Park JH, Ahn RS, et al. (2004): Molecular mechanism of suppression of testicular steroidogenesis by proinflammatory cytokine tumor necrosis factor alpha. Mol Cell Biol 24: 2593-2604.

50. Terranova PF, Rice VM (1997): Review: Cytokine involvement in ovarian process. Am J Reprod Immunol 37: 50-63.

51. Hales DB, Diemer T, Hales KH (1999): Role of cytokines in testicular function. Endocrine 10: 201-217.

52. Ahmed SF, Farquharson C (2007): Interleukin-6 (IL-6) inhibits growth hormone $(\mathrm{GH})$-mediated gene expression in hepatocytes. Am J Physiol Gastrointest Liver Physiol 292: G1793-G1803.

53. Denson LA, Menon RK, Shaufl A, et al. (2001): TNF- $\alpha$ downregulates murine hepatic growth hormone receptor expression by inhibiting Sp1 and Sp3 binding. J Clin Invest 107: 1451-1458.

54. Denson LA, Held MA, Menon RK, et al. (2003): Interleukin-6 inhibits hepatic growth hormone signaling via upregulation of Cis and Socs-3. Am J Physiol Gastrointest Liver Physiol 284: G646-G654

55. Soendergaard C, Kvist PH, Thygesen P, et al. (2017): Characterization of Growth Hormone Resistance in Experimental and Ulcerative Colitis. Int J Mol Sci 18: 2046.

56. Wang P, Li N, Li JS, Li WQ (2002): The role of endotoxin, TNF-alpha, and IL-6 in inducing the state of growth hormone insensitivity. World J Gastroenterol 8: 531-536.

57. Ahmed T, Yumet G, Shumate M, et al. (2006): Tumor necrosis factor inhibits growth hormone-mediated gene expression in hepatocytes. Am J Physiol Gastrointest Liver Physiol 291: G35-G44.

58. Erman A, Wabitsch M, Goodyer CG (2011): Human growth hormone receptor (GHR) expression in obesity: II. Regulation of the human GHR gene by obesity-related factors. Int J Obes 35: 1520-1529.

59. De Benedetti F, Meazza C, Oliveri M, et al. (2001): Effect of IL-6 on IGF binding protein-3: a study in IL-6 transgenic mice and in patients with systemic juvenile idiopathic arthritis. Endocrinology 142: 4818-4826.

60. De Benedetti F, Meazza C, Martini A (2002): Role of interleukin-6 in growth failure: an animal model. Horm Res 58: 24-27.

61. Fernandez-Vojvodich P, Palmblad K, Karimian E, et al. (2012): Pro-inflammatory cytokines produced by growth plate chondrocytes may act locally to modulate longitudinal bone growth. Horm Res Paediatr 77: 180-187.

62. Nakajima S, Naruto T, Miyamae T, et al. (2009): Interleukin-6 inhibits early differentiation of ATDC5 chondrogenic progenitor cells. Cytokine 47: 91-97.

63. Fernandez-Vojvodich P, Zaman F, Sävendahl L (2013): Interleukin- 6 acts locally on the growth plate to impair bone growth. Ann Rheum Dis 72: e24.

64. Fernandez-Vojvodich P, Karimian E, Sävendahl L (2011): The biologics anakinra and etanercept prevent cytokine-induced growth retardation in cultured fetal rat metatarsal bones. Horm Res Paediatr 76: 278-285. 
65. Gaspari S, Marcovecchio ML, Breda L, Chiarelli F (2011): Growth in juvenile idiopathic arthritis: the role of inflammation. Clin Exp Rheumatol 29: 104-110.

66. Street ME, de'Angelis G, Camacho-Hübner C, et al. (2004): Relationships between serum IGF-1, IGFBP-2, interleukin-1beta and interleukin-6 in inflammatory bowel disease. Horm Res 61: 159-164.

67. Beattie RM, Camacho-Hübner C, Wacharasindhu S, et al. (1998): Responsiveness of IGF-I and IGFBP-3 to therapeutic intervention in children and adolescents with Crohn's disease. Clin Endocrinol 49: 483-489.

68. Street ME, Ziveri MA, Spaggiari C, et al. (2006): Inflammation is a modulator of the insulin-like growth factor (IGF)/ IGF-binding protein system inducing reduced bioactivity of IGFs in cystic fibrosis. Eur J Endocrinol 154: 47-52.

69. Patel L (2007): Growth and chronic disease. Ann Nestlé 65: 129-136.

70. Ballinger AB, Azooz O, El-Haj T, et al. (2000): Growth failure occurs through a decrease in insulin-like growth factor 1 which is independent of undernutrition in a rat model of colitis. Gut 46: 694-700.

71. Shamir R, Phillip M, Levine A (2007): Growth retardation in pediatric Crohn's disease: Pathogenesis and interventions. Inflamm Bowel Dis 13: 620-628.

72. Sikorska D, Rutkowski R, Łuczak J, et al. (2018): No effect of anti-TNF- $\alpha$ treatment on serum IL-17 in patients with rheumatoid arthritis. Cent Eur J Immunol 43: 270-275.

73. Vilaiyuk S, Lerkvaleekul B, Soponkanaporn S, et al. (2019): Correlations between serum interleukin-6, serum soluble interleukin-6 receptor, and disease activity in systemic juvenile idiopathic arthritis patients treated with or without tocilizumab. Cent Eur J Immunol 44: 150-158.

74. Taylor AM, Bush A, Thomson A, et al. (1997): Relation between insulin-like growth factor-I, body mass index, and clinical status in cystic fibrosis. Arch Dis Child 76: 304-309.

75. Tsatsoulis A, Siamopoulou A, Petsoukis Ch, et al. (1999): Study of growth hormone secretion and action in growth-retarded children with juvenile chronic arthritis (JCA). Growth Horm IGF Res 9: 143-149.

76. Allen RC, Jimenez M, Cowell CT (1991): Insulin-like growth factor and growth hormone secretion in juvenile chronic arthritis. Ann Rheum Dis 50: 602-606.

77. Gupta N, Lustig RH, Kohn MA, et al. (2011): Sex differences in statural growth impairment in Crohn's disease: role of IGF-1. Inflamm Bowel Dis 17: 2318-2325.

78. Bozzola E, Pagani S, Meazza C, et al. (2012): Changes in growth hormone receptor gene expression during therapy in children with juvenile idiopathic arthritis. Horm Res Paediatr 77: $52-58$.

79. Bechtold S, Beyerlein A, Ripperger P, et al. (2012): Total pubertal growth in patients with juvenile idiopathic arthritis treated with growth hormone: Analysis of a single center. Growth Horm IGF Res 22: 180-185.

80. Saha MT, Haapasaari J, Hannula S, et al. (2004): Growth hormone is effective in the treatment of severe growth retardation in children with juvenile chronic arthritis. Double blind placebo-controlled followup study. J Rheumatol 31: 1413-1417.

81. Grote FK, Van Suijlekom-Smit LW, Mul D, et al. (2006): Growth hormone treatment in children with rheumatic disease, corticosteroid induced growth retardation, and osteopenia. Arch Dis Child 91: 56-60.

82. Sarzi-Puttini P, Atzeni F, Schölmerich J, et al. (2006): AntiTNF antibody treatment improves glucocorticoid induced insulin-like growth factor 1 (IGF1) resistance without influencing myoglobin and IGF1 binding proteins 1 and 3. Ann Rheum Dis 65: 301-305.

83. MacRae VE, Wong SC, Smith W, et al. (2007): Cytokine profiling and in vitro studies of murine bone growth using biological fluids from children with juvenile idiopathic arthritis. Clin Endocrinol 67: 442-448.

84. Kirschner BS, Sutton MM (1986): Somatomedin-C levels in growth-impaired children and adolescents with chronic inflammatory bowel disease. Gastroenterology 91: 830-836.

85. Wong SC, Smyth A, McNeill E, et al. (2010): The growth hormone insulin-like growth factor 1 axis in children and adolescents with inflammatory bowel disease and growth retardation. Clin Endocrinol 73: 220-228.

86. Thomas AG, Holly JM, Taylor F (1993): Insulin like growth factor-I, insulin like growth factor binding protein-1 and insulin in childhood Crohn's disease. Gut 34: 944-947.

87. Farthing MJ, Campbell CA, Walker-Smith J, et al. (1981): Nocturnal growth hormone and gonadotrophin secretion in growth retarded children with Crohn's disease. Gut 22: 933-938.

88. Cezard JP, Touati G, Alberti C, et al. (2002): Growth in Paediatric Crohn's Disease. Horm Res 58: 11-15.

89. Vortia E, Kay M, Wyllie R (2011): The role of growth hormone and insulin-like growth factor-1 in Crohn's disease: implications for therapeutic use of human growth hormone in pediatric patients. Curr Opin Pediatr 23: 545-551.

90. Chong SK, Grossman A, Walker-Smith JA, Rees LH (1984): Endocrine dysfunction in children with Crohn's disease. J Pediatr Gastroenterol Nutr 3: 529-534.

91. Ciro D, Padoan R, Blau H, et al. (2013): Growth retardation and reduced growth hormone secretion in cystic fibrosis. Clinical observations from three CF centers. J Cyst Fibros 12: 165-169.

92. Pagani S, Bozzola E, Acquafredda G, et al. (2019): GH-IGF-1 Axis in children with cystic fibrosis. Clin Med Res 17: 82-89.

93. Le TN, Anabtawi A, Putman MS, et al. (2019): Growth failure and treatment in cystic fibrosis. J Cyst Fibros 18: S82-S87.

94. Street ME, Spaggiari C, Volta C, et al. (2009): The IGF system and cytokine interactions and relationships with longitudinal growth in prepubertal patients with cystic fibrosis. Clin Endocrinol 70: 593-598.

95. Ozen M, Cokugras H, Ozen N, et al. (2004): Relation between serum Insulin-like growth factor-I and insulin-like growth factor-binding protein-3 levels, clinical status and growth parameters in prepubertal cystic fibrosis patients. Pediatr Int 46: 429-435.

96. Lebl J, Zahradníková M, Bartosová J, et al. (2001): Insulin-like growth factor-I and insulin-like growth factorbinding protein-3 in cystic fibrosis: a positive effect of antibiotic therapy and hyperalimentation. Acta Paediatr 90: 868-872.

97. Gifford AH, Nymon AB, Ashare A (2014): Serum insulin-like growth factor-1 (IGF-1) during CF pulmonary exacerbation: trends and biomarker correlations. Pediatr Pulmonol 49: 335-341.

98. Oglesby IK, Vencken SF, Agrawal R, et al. (2015): miR-17 overexpression in cystic fibrosis airway epithelial cells decreases interleukin-8 production. Eur Respir J 46: 1350-1360.

99. Mooney C, McKiernan PJ, Raoof R, et al. (2020): Plasma microRNA levels in male and female children with cystic fibrosis. Sci Rep 10: 1141. 
100. Wang H, Zhang S, Yu Q, et al. (2016): Circulating microRNA223 is a new biomarker for inflammatory bowel disease. Medicine (Baltimore) 95: e2703.

101. Sun J, Feng M, Wu F, et al. (2016): Plasma miR-26a as a diagnostic biomarker regulates cytokine expression in systemic juvenile idiopathic arthritis. J Rheumatol 43: 16071614.

102. Demir F, Çebi AH, Kalyoncu M (2018): Evaluation of plasma microRNA expressions in patients with juvenile idiopathic arthritis. Clin Rheumatol 37: 3255-3262. 